\title{
PARAMETERS OF THE INTELLIGENT DRIVER MODEL IN SIGNALIZED INTERSECTIONS
}

\author{
Tamás Kovács, Kálmán Bolla, Rafael Alvarez Gil, Edit Csizmás, Csaba Fábián, Lóránt Kovács, \\ Krisztián Medgyes, József Osztényi, Attila Végh
}

Original scientific pape In the present paper the constant parameters of the (car following) Intelligent Driver Model are calibrated so as to obtain correct flow capacities of a signalized intersection. The calibration is based on measured time-headway parameters of the consecutive vehicles. The measurement data were taken from the work published by Dey et al. The parameters were calibrated partly by numeric calculations and partly by computer simulation, which was developed by the authors of this paper. The simulated environment was a single lane road terminated by a signalized intersection with a queue of stopped cars. As the result of the calibration, the model produced the measured saturated time-headway constant in the stationary flow phase and gave a good approximation of the consecutive time-headways in the initial transient phase. It was found that the calibrated constants of the Intelligent Driver Model considerably differ from the values proposed for modelling traffic on motorways: in a signalized intersection situation higher maximal acceleration and lower safe time gap parameters should be applied. More precisely, the differences are about $30 \%$ in each case.

Keywords: Intelligent Driver Model; signalized intersection; traffic simulation

Parametri modela inteligentnog vozača u signaliziranim križanjima

Izvorni znanstveni članka

U ovom su radu kalibrirani nepromjenjivi parametri Modela inteligentnog vozača (auta koji slijedi) kako bi se dobila točna propusna moć signaliziranog križanja. Kalibriranje se zasniva na izmjerenim parametrima intervala između dvaju vozila u nizu. Podaci mjerenja su uzeti iz rada u izdanju Dey et al. Parametri su kalibrirani djelomično numeričkim kalkulacijama i djelomično računalnom simulacijom, koju su razvili autori ovoga rada. Simulirano okruženje bila je traka koja je završavala signaliziranim križanjem s redom zaustavljenih vozila. Kao rezultat kalibriranja, model je davao izmjerenu konstantu zasićenja između dvaju vozila u nizu u fazi saobraćaja u mirovanju te je dao dobru aproksimaciju vremena između dvaju vozila u nizu u početnoj prolaznoj fazi. Ustanovljeno je da se kalibrirane konstante Modela inteligentnog vozača znatno razlikuju od vrijednosti predloženih za modeliranje prometa na autocestama: kad se radi o signaliziranim križanjima trebalo bi primijeniti parametre većeg maksimalnog ubrzanja i manjeg intervala sigurnog slijeda između dvaju vozila. Točnije, postoje razlike od oko $30 \%$ u svakom slučaju.

Ključne riječi: Model inteligentnog vozača; signalizirano križanje; simulacija prometa

\section{Introduction}

Recently the usage of traffic simulators in research and traffic engineering has been growing gradually as the computational power becomes cheaper. These simulators give us cheap and quick answers about solutions to new intersections or urban traffic systems prior to expensive experiments and implementations.

One of the two main simulator-types is the macroscopic simulator. This does not follow the (microscopic) movements of the individual vehicles, but calculates the time evolution of the integral quantities of traffic such as the vehicle density, the flow rate (passed vehicles per hour through a certain point of a road), and the mean travel time on a specific route [1]. In order to find the solution, these systems assume the prior knowledge of the coupling factors between the connected road segments, which are typically the maximal flow rates accessible between the two connected elements. Due to their integral nature, macroscopic simulators offer a very fast solution for the problems, where the microscopic behaviour is completely taken into consideration by the coupling constants mentioned above (see for example [2]).

The other main branch consists of the microscopic simulators, where the individual movement of each vehicle is calculated. In this case the coupling constants of the neighbouring lanes are obtained by simulator, and the only necessary prior knowledge is the detailed geometry of the road-lanes and the parameters of the physical model governing the vehicle movement.
It was shown by Péter et al. that if a macroscopic model has a validated set of coupling constants then it is able to predict the time-evolution of the measured velocity and density functions with high accuracy under a few seconds of computation ([3] and [4]). This makes possible to develop an effective hybrid simulation system that employs a micro-model for calculating the coupling constants at hand (sparing expensive measurements), and a macro model for getting the time evolution of an optimized traffic flow. Moreover, such accurate macroscopic models can serve as bases of validation and further improvements of various microscopic models.

The basic element of a micro-simulation is the so called car following model and, generally, this is extended with a compatible lane-changing model. The first practically applicable car following model was published by Wiedemann in 1974 [5], and later Fritzsche developed another model [6] using similar mathematical approach as Wiedemann. These so called "psycho-physical" models assume different behaviours (and equations) in different states of the following driver. These states (e.g. "free move", "approaching", "emergency braking", etc.) are separated from each other by border-lines in the two dimensional phase-space of the velocity difference and the following distance. Recently an improved version of the Wiedemann model was developed [7], which is more capable to simulate traffic on motorways. In spite of the improvements these models can result in local instabilities in the movement of the follower vehicles, especially when there are numerous followers in a convoy [8].

A different approach is the "Intelligent Driver Model" (IDM) published by Treiber et al. [9, 10]. In order to 
overcome the instabilities of the state based models, the idea of the behaviour-states was omitted; and, based on a statistical physical analogy, a single equation of motion was developed to govern the motion of each vehicle in all situations.

In the past years the IDM attracted high attention in this field: validation tests, parameter calibrations and

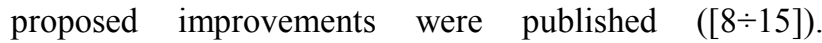
However, most of the applications focused on motorways i.e. long lanes with no intersections. Besides, Treiber and Kesting give proposed parameter values for the case of urban traffic in [10]. In the last year S. Yang calibrated the parameters of the IDM for the case of a signalized intersection [15]. He studied the motion of the IDM vehicles after the signal changed to green, and optimized the IDM parameter values so as to minimize the difference between the simulated and measured trajectories values of four observed vehicles (from the second to the $5^{\text {th }}$ ). He obtained different IDM parameter values from those proposed for the motorway case.

In the case of an urban traffic environment, one of the most important quantities is the maximal flow capacity of an intersection, which is given in vehicle/hour units and widely used by traffic engineers. Young's effort seems to be a pioneering work in order to use IDM for flowcapacity calculation of signalised intersections. However, since Young's method is based only on trajectories of four vehicles, it needs further refinements to achieve universally applicable solution.

In the present paper a new IDM parameter identification method will be presented by which a more accurate estimation can be given for the maximal flowcapacity of a general signalized intersection. In this work we apply the physical measurement data published recently by Dey et al. [17]. It is worth mentioning that there are also available such measurements earlier published (see for example [18] or [19]).

In the next Section the (basic) IDM is introduced. In Section 3 the proposed method of the parameter calibration is detailed. In Section 4 the results of the calibration and the tests are presented, and in the last section we give conclusions.

\section{The intelligent driver model}

In a vehicle following model the three dynamically changing input quantities are the following:

- $\quad$ the velocity of the vehicle, here denoted by $v$;

- the velocity difference between the leader vehicle and the vehicle at hand, that is $\Delta v=v-v_{1}$;

- the bumper to bumper distance from the leader vehicle, here denoted by $s$.

Based on these quantities, the equation of motion of the IDM is given as

$$
\frac{\mathrm{d}}{\mathrm{d} t} v=a \cdot\left[1-\left(\frac{v}{v_{0}}\right)^{\delta}-\left(\frac{s^{*}(v, \Delta v)}{s}\right)^{2}\right]
$$

where $s^{*}(v, \Delta v)$ is the characteristic following distance and given by

$$
s^{*}(v, \Delta v)=s_{0}+s_{1} \cdot \sqrt{\frac{v}{v_{0}}}+T \cdot v+\frac{v \cdot \Delta v}{2 \sqrt{a \cdot b}},
$$

The fixed parameters of the IDM are summarized in Tab. 1.

Table 1 Parameters of the IDM

\begin{tabular}{|c|l|c|}
\hline Parameter & Definition & Units \\
\hline$a$ & maximal positive acceleration & $\mathrm{m} / \mathrm{s}^{2}$ \\
\hline$b$ & maximal negative acceleration & $\mathrm{m} / \mathrm{s}^{2}$ \\
\hline$v_{0}$ & maximal velocity & $\mathrm{m} / \mathrm{s}$ \\
\hline$T$ & following time-gap & $\mathrm{s}$ \\
\hline$s_{0}$ & static bumper-to-bumper distance & $\mathrm{m}$ \\
\hline$s_{l}$ & dynamic bumper-to-bumper distance & $\mathrm{m}$ \\
\hline$\delta$ & acceleration exponent & - \\
\hline$L$ & vehicle length & $\mathrm{m}$ \\
\hline
\end{tabular}

The vehicle length parameter $(L)$ explicitly is not present in Eqs. (1) and (2), but it is used in the relationship:

$$
s=\Delta x-L,
$$

where $\Delta x$ is the distance between the centres of vehicles.

It can be seen that the characteristic following distance $\left(s^{*}\right)$ contains three terms depending on the velocity: the term $T \cdot v$ gives the distance travelled by the vehicle under the following time-gap; the last term takes into consideration the difference of velocities, while the term with the coefficient $s_{1}$ introduces a dependence on the ratio $v / v_{0}$. It is widely agreed (see for example [9] or [11]) that in most of the cases this latter term is not necessary for modelling usual traffic problems, since the ratio $v / v_{0}$ is also present in Eq. (1) and therefore the parameter $s_{1}$ is taken to be zero in most of the cases. Considering this, (and for the sake of simplicity), we will also set $s_{1}=0$.

The stationary solution of Eq. (1) has high importance in the IDM. This is the case when the acceleration function is identical with zero. This solution (with $s_{1}=0$ ) can be given by

$$
s=\frac{s_{0}+T \cdot v}{\sqrt{1-\left(v / v_{0}\right)^{\delta}}}
$$

(see [10] or [13]). This determines the following distance $s$ in a convoy, the leader of which proceeds with the fixed velocity of $v$. In the next section this stationary solution will be important for us.

\section{The method of the parameter calibration 3.1 The time-headway parameter and the flow capacity}

As it was mentioned in the introduction, our aim is to calibrate the fixed IDM parameters so as to get the correct maximal flow capacity (here denoted by $Q$ ) of an intersection. This capacity is measured as the maximal number of Passenger Car Units (PCUs) passes through the intersection during an hour (vehicle/hour), provided that the other side of the intersection is free i.e. there is no 
other bottleneck beyond the green time. In our simulations this condition was ensured. "Passenger Car Unit" means an average passenger car with specific parameters and the vehicles of different types are expressed with this unit: for example a long truck is generally taken to be 3 PCUs.

Some of the constant parameters will not be calibrated, but kept fixed. According to other works [8, 9, $11,12,13]$ these parameters and values are the following: $b=2 \mathrm{~m} / \mathrm{s}^{2} ; v_{0}=15,28 \mathrm{~m} / \mathrm{s}(55 \mathrm{~km} / \mathrm{h}) ; \delta=4$ and $L=4 \mathrm{~m}$. So, only the remaining three parameters $a, T$ and $s_{0}$ will be subject to calibration. It will be shown that our aim can be achieved by the calibration of these three parameters.

The flow capacity above is determined solely by the total green-time during an hour and the time-headways between the consecutive cars. The time-headway is given as the time-interval between the moments that the front bumpers of two consecutive cars pass the same point on the road. (Note that the time-headway is different from the "following time-gap" parameter of the IDM.) At a signalized intersection the time-headways after the lamp changes to green can be given by a series as illustrated in Fig. 1 (see for example [16]). In this situation the zero time headway is considered to be the time-interval between the moment of the green-signal start and the moment when the reference point of the first unit vehicle passes the stop line (or the place of the sensor).

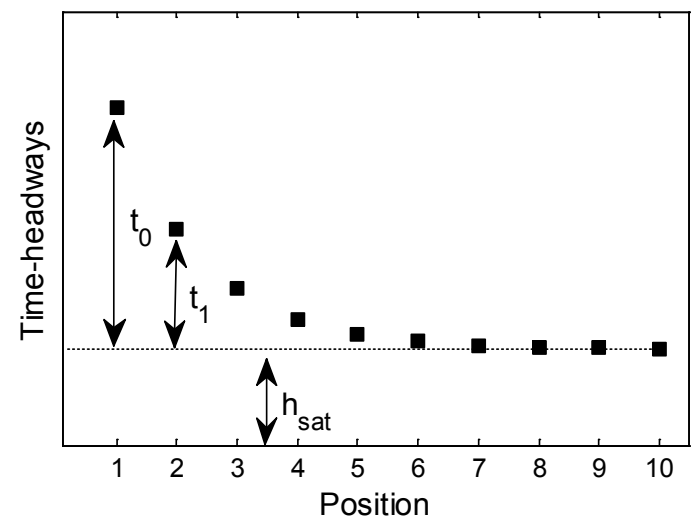

Figure 1 Illustration of the first ten time-headway values after the green signal

As it is shown in the figure, with the increasing rowposition index the time-headway value tends to a constant, which is called as the "saturated time-headway" value and denoted by $h_{\text {sat }}$. It is usual to express the $i^{\text {th }}$ time-headway value by $h_{\text {sat }}$ as

$H_{i}=h_{\text {sat }}+t_{i}, \quad \mathrm{i}=0,1,2, \ldots$

where $t_{i}$ is the increment of the $i^{\text {th }}$ time-headway compared to $h_{\text {sat }}$. Since only the first $5 \div 7 t_{i}$ parameters differ from zero more than the measuring error, these values are taken to be zero beyond a certain index. In the present work we take $t_{i}=0$ if $i>5$.

If NPCUs pass the intersection during a green period, then the length of one green period (denoted by $G$ ) is equal to
$G=N \cdot h_{\text {sat }}+\sum_{i=0}^{5} t_{i}$

On the other hand $N$ can be expressed as

$N=\frac{P}{3600} Q$

where $P$ is the length of a total signal-period expressed in seconds.

From Eqs. (6) and (7) we get the relationship between the $Q$ maximal capacity and $h_{\text {sat }}$ as

$$
Q=\frac{3600}{P} \cdot \frac{1}{h_{\mathrm{sat}}} \cdot\left(G-\sum_{i=0}^{5} t_{i}\right) .
$$

\subsection{Calibrating the parameter $T$}

Let's examine first only the phase, when the PCUs beyond the $5^{\text {th }}$ pass the intersection. In this phase the consecutive time-headway values are equal to the constant $h_{\text {sat }}$. This is a static flow situation, and it can be modelled by the static solution of the IDM detailed in the introduction (see Eq. (4)). Let's denote by $v_{\text {sat }}$ the speed limit applied to the convoy leader, and therefore to all of the followers. The relationship between $v_{\text {sat }}$ and $h_{\text {sat }}$ is:

$v_{\text {sat }} \cdot h_{\text {sat }}=s+L$,

where $s$ is the bumper to bumper distance given by Eq. (4). Using Eq. (4) we get:

$$
h_{\mathrm{sat}}=\frac{1}{\sqrt{1-\left(\frac{v_{\mathrm{sat}}}{v_{0}}\right)^{\delta}}} \cdot\left(\frac{s_{0}}{v_{\mathrm{sat}}}+T\right)+\frac{L}{v_{\mathrm{sat}}} .
$$

In order to construct our reliable IDM, we have to find the value of $v_{\text {sat }}$ based on the measured value of $h_{\text {sat }}$ [17]. However, Eq. (10) is not solvable for $v_{\text {sat }}$, so we need to apply a numerical method.

Fig. 2 shows the graphs of the $h_{\text {sat }}\left(T, v_{\text {sat }}\right)$ functions for various values of the IDM parameter $T$. (In calculating these graphs we used $s_{0}=2,0 \mathrm{~m}$.) The value of $h_{\text {sat }}=1,56$ sec, measured by Dey et al., is represented by a vertical dashed line.

It is known from macroscopic models (see for example [10] chapter 8) that the outflow from a congested zone to a free-traffic zone is maximal and this maximum flow is proportional to the reciprocal of $h_{\text {sat }}$. This means that for a fixed value of $T$ the outflow parameters are given by the minimum point of the specific iso- $T$ curve (iso- $T$ curves are drawn by continuous lines in Fig. 2). The curve that has the minimum equal to the measured value $\left(h_{\mathrm{sat}}=1,56 \mathrm{~s}\right)$ belongs to $T=0,86 \mathrm{~s}$, and the minimum point is at $v_{\text {sat }}=10,24 \mathrm{~m} / \mathrm{s}(36,85 \mathrm{~km} / \mathrm{h})$.

In general we can write that:

$\min \left\{h_{\text {sat }}\left(T_{\text {cal }}, v_{\text {sat }}\right)\right\}=h_{\text {sat, measured }}$ 
where $T_{\text {cal }}$ is the calibrated value of the $\mathrm{T}$ parameter (here $0,86 \mathrm{~s}$ ), and the minimum place is the calibrated value of the $v_{\text {sat }}$ parameter (here $10,24 \mathrm{~m} / \mathrm{s}$ ).

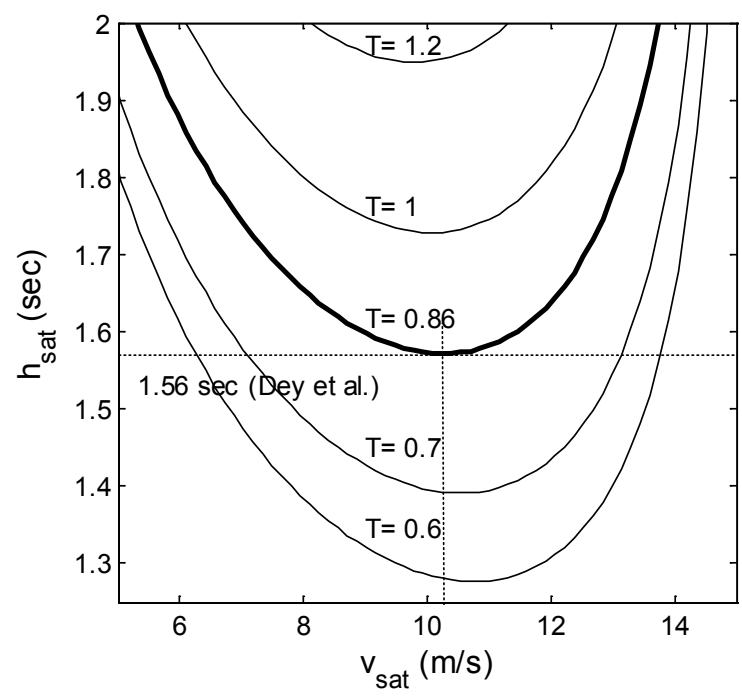

Figure 2 The graphs of the $h_{\text {sat }}\left(T, v_{\text {sat }}\right)$ functions for various values of the IDM parameter $T$

\subsection{Calibrating the parameters $a$ and $s_{0}$}

The maximal acceleration parameter $(a)$ of the IDM does not play any role in the stationary phase discussed in Subsection 3.2. Therefore, this parameter can be calibrated only with the help of the first phase, when the first six vehicles pass the stop line. (This is the time interval of the first $14 \div 16$ seconds after the green ignition.) In this phase the consecutive time-headways $\left(H_{i}\right)$ are given by the sum of $h_{\text {sat }}$ and a non-zero $t_{i}$ term (see Eq. (5) and Fig. 1). These $t_{i}$ additive terms can be obtained also from published measurements [14, 16, 17].

As it was defined above, the first time-headway is the time interval between the start of the green signal and the moment when the reference point of the first vehicle passes the stop line. Shortly after the vehicle start i.e. in the low speed region the acceleration is approximately constant and equal to $a$. So the way of the vehicle can be well approximated by the $(a / 2) \cdot t^{2}$ formula. Based on these, the way of the first vehicle from the start-point to the intersection's stop line (denoted by $L_{\text {stop }}$ here) is

$L_{\text {stop }}=\frac{a}{2}\left(h_{\text {sat }}+t_{0}\right)^{2}$

The virtual detector recording the passing times is placed at the stop line. Since $L_{\text {stop }}$ is a new parameter that should be also calibrated, this relationship (Eq. (12)) will be used to find the value of $L_{\text {stop }}$ provided that the values $h_{\text {sat }}, t_{0}$ and $a$ are known.

The proper choice of the calibrated value of $L_{\text {stop }}$ ensures that the model yields the measured value of $t_{0}$ for arbitrary $a$ and $h_{\text {sat }}$ values. Similarly, the proper choice of the calibrated $a$ and $s_{0}$ values the model yields the measured parameter values of $t_{1}, t_{2}, \ldots t_{5}$.

For this latter calibration procedure we will employ a simple numeric parameter optimization. With the help of a computer simulation (developed by the authors of this paper) we can calculate the $t_{1}, t_{2}, \ldots t_{5}$ parameters produced by the IDM. The simulated environment was a single lane road terminated by a signalized intersection with a queue of stopped PCUs. The row of vehicles (governed by the IDM) started immediately after the green signal. Let us denote the simulated values of the $t_{i}$ parameters by $t_{i}^{\text {sim }}$ and introduce the standard deviation of the measured and simulated values as

$\overline{\operatorname{STD}}\left(a, s_{0}\right)=\sqrt{\frac{1}{5} \sum_{i=1}^{5}\left(t_{i}^{\mathrm{sim}}-t_{i}\right)^{2}}$.

This standard deviation (STD) obviously depends on the parameters of the IDM. In order to get the best fit of the simulated values to the measured ones, we have to find the minimum place of the $S T D$ functional, and hence the calibrated values of $a$ and $s_{0}$.

\subsection{The algorithm of the proposed calibration process}

The numeric calculations detailed in the Subsections 3.2 and 3.3 cannot give the calibrated parameters $T, v_{\text {sat }}, a$ and $s_{0}$ in a single step, because the parameter $s_{0}$ plays a role in both calibration methods. Therefore we propose the procedure as follows:

1) Initialize the fixed parameters $\left(b=2 \mathrm{~m} / \mathrm{s}^{2} ; v_{0}=15,27\right.$ $\mathrm{m} / \mathrm{s}(55 \mathrm{Km} / \mathrm{h}) ; \delta=4$ and $L=4 \mathrm{~m})$;

2) For each value of $s_{0}$ in a parameter-set $S_{0}$ do:

Using the Eq. (11) determine calibrated values of $T$ and $v_{\text {sat }}$;

For each value of $a$ in a parameter-set $A$ determine the value of $\operatorname{STD}\left(a, s_{0}\right)$ defined in Eq. (13);

3) Find the calibrated values of $T, v_{\text {sat }}, a$ and $s_{0}$ as the minimum place of the $S T D$ functional given in Eq. (13);

4) Using the calibrated value of $a$ calculate the value of $L_{\text {stop }}$ as given in Eq. (12).

\section{The results and tests of the parameter calibration}

Earlier studies $[9 \div 12]$ about the IDM in a motorway situation propose the values $2,0 \div 3,0 \mathrm{~m}$ for $s_{0}$, and $0,9 \div$ $1,4 \mathrm{~m} / \mathrm{s}^{2}$ for $a$. However we expect somewhat smaller $s_{0}$ and higher $a$ values at a signalized intersection, therefore we start out from the parameter sets $S_{0}=\{1,0 ; 1,05 ; 1,10$; $\ldots 3,0 \mathrm{~m}\}$ and $A=\left\{1,0 ; 1,05 ; 1,10 ; \ldots 3,0 \mathrm{~m} / \mathrm{s}^{2}\right\}$, which includes also the value-range proposed for motorways.

The measured values [13] of the $t_{i}$ parameters applied in the Step 3 of the proposed algorithm were: $t_{0}=1,39 ; t_{1}$ $=1,02 ; t_{2}=0,56 ; t_{3}=0,34 ; t_{4}=0,29 ; t_{5}=0,06 \mathrm{~s}$.

Following the steps of the proposed algorithm, the obtained contour plot of the surface of the $\operatorname{STD}\left(a, s_{0}\right)$ function is shown in Fig. 3. As it can be seen, there is no point-like minimum-place in the $\left(a, s_{0}\right)$ parameter space, but the STD has its global minimum places along an approximately straight line shown by a thick dashed line in the figure.

This means that we are free to choose an arbitrary $s_{0}$ parameter value (in the range of $1,0 \div 3,0$ ) and this chosen value determines the corresponding value of $a$. The values of $s_{0}$ proposed for motorways usually are in the range of $2,0 \div 3,0 \mathrm{~m}$. In a vehicle-row at a signalized intersection a lower value can be expected that in a jammed motorway, 
therefore, here we choose the value $s_{0}=2,0 \mathrm{~m}$, i.e. the lowest value in the range above. The value of $a$, that corresponds to $s_{0}=2,0 \mathrm{~m}$ is $1,62 \mathrm{~m} / \mathrm{s}^{2}$ (see Fig. 3).

The final calibrated values, together with the parameter values calibrated recently for motorways by Schakel et al. [11] and those that were proposed in [10] for city traffic are given in Tab. 2. The $L$ and the $s_{0}$ parameters are not calibrated but chosen as fixed in both parameter sets.

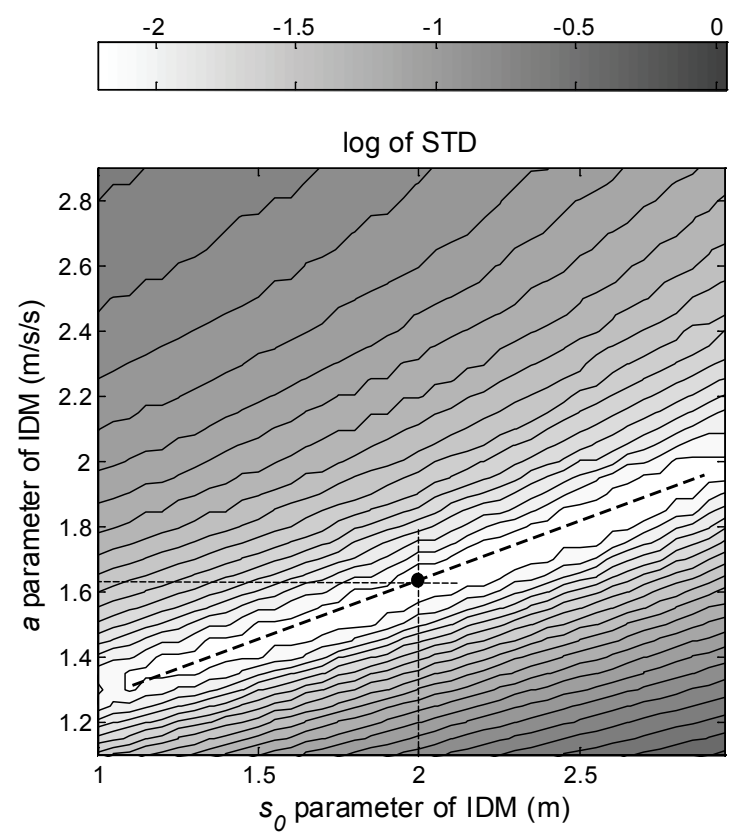

Figure 3 The contour plot of the Standard Deviation of the measured and the simulated $t_{i}$ parameters $(0<i<0)$ as a function of the maximal acceleration and the static bumper-to bumper distance

Table 2 The IDM parameters calibrated for the case of signalized intersections and those validated for motorways

\begin{tabular}{|c|c|c|c|c|}
\hline \multicolumn{5}{|c|}{ intersections and those validated for motorways } \\
$\begin{array}{c}\text { Calibrated } \\
\text { values for } \\
\text { inter }\end{array}$ & $\begin{array}{c}\text { Calibrated } \\
\text { values for } \\
\text { (present paper) }\end{array}$ & $\begin{array}{c}\text { Proposed } \\
\text { motorways } \\
\text { (Schakel) }\end{array}$ & $\begin{array}{c}\text { (Treiber and } \\
\text { Kesting) }\end{array}$ & Units \\
\hline$T$ & 0,86 & 1,2 & 1,0 & $\mathrm{~s}$ \\
\hline$v_{\text {sat }}$ & 10,3 & - & - & $\mathrm{m} / \mathrm{s}$ \\
\hline$a$ & 1,6 & 1,25 & 1,0 & $\mathrm{~m} / \mathrm{s}^{2}$ \\
\hline$s_{0}$ & 2,0 & 3,0 & 2,0 & $\mathrm{~m}$ \\
\hline$L$ & 4,0 & 4,0 & - & $\mathrm{m}$ \\
\hline$L_{\text {stop }}$ & 7.1 & - & - & $\mathrm{m}$ \\
\hline
\end{tabular}

As it can be seen, the value of $\mathrm{T}$ calibrated for the traffic sign case is quite close to the value proposed for cities in [10] and somewhat further from that of calibrated for motorways. The presently calibrated value of the $a$ parameter, however, is considerably higher than those of the two referred parameter sets. This may be due to the fact that the drivers tend to apply higher accelerations when starting at a green sign compared to other urban traffic situations.

Fig. 4 shows the comparison of the measured (Dey et al. [17]) and the simulated time-headway values. The simulated values were calculated by the IDM parameterset calibrated here ("intersection parameter-set") and also by the IDM parameter-set calibrated by Schakel el al. ("freeway parameter-set"). In the case of this latter one there was no speed-limit $\left(v_{\text {sat }}\right)$ applied to the leader vehicle, and the highest speed was $v_{0}=15,27 \mathrm{~m} / \mathrm{s}(55$ $\mathrm{km} / \mathrm{h})$.

The first values match almost exactly; because the choice of the $L_{\text {stop }}$ parameter ensures this (see the Eq. (12)). Beyond the $6^{\text {th }} \div 8^{\text {th }}$, both of the measured and the simulated values of the intersection parameter-set approach the measured $h_{\text {sat }}$ value $(1,57)$, though the measured values show some fluctuations, which cannot be reproduced by the IDM. The simulated values of the freeway parameter-set, however, approach a considerably higher $h_{\text {sat }}$ value, which is due to the absence of the speed limit $v_{\text {sat }}$ and the higher values of $T$ and $s_{0}$. These simulated values are also high above the other two curves, in positions $1 \div 8$ because of the lower value of $a$.

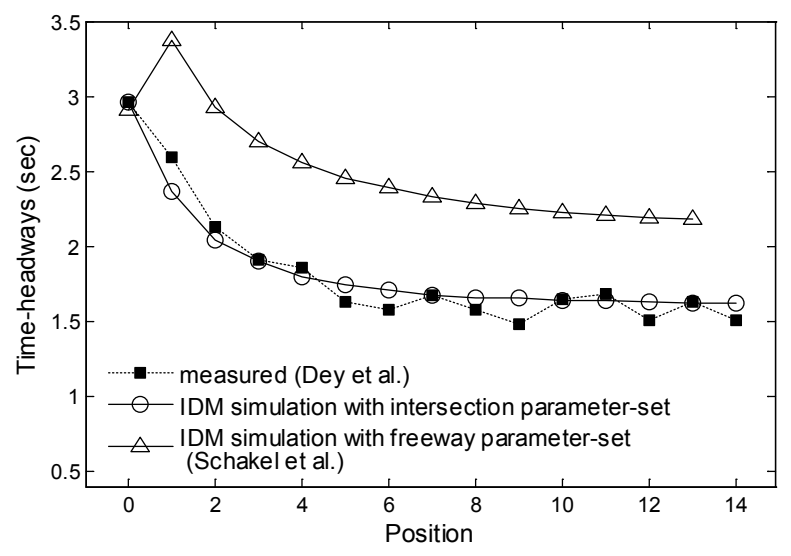

Figure 4 The measured and the simulated time-headway values

\section{Conclusion}

In this paper a new calibration method for IDM parameter-set $\left(T, a, s_{0}, L\right)$ has been introduced. In order to achieve sufficient precision in modelling the consecutive time-headways at a signalized intersection, two additional parameters have to be introduced:

- the $v_{\text {sat }}$ (smaller than $v_{0}$ ) parameter that determines a speed limit for the leader vehicle when passing through the intersection;

- $\quad$ the $L_{\text {stop }}$ parameter that determines the distance of the reference point of the leader vehicle from the stop line when the sign is red.

By the calibration of the extended parameter set $(T, a$, $\left.s_{0}, L, v_{\text {sat }}, L_{\text {stop }}\right)$, the IDM has been proven to be a proper tool to simulate measured time-headways of signalized intersections, as it is demonstrated by Figure 4.

The precise approximation of the time-headway values implies the correct approximation of the maximal flow capacity of an intersection (provided that the signal program is known).

The calibrated IDM parameter value of a signalized intersection differs from that of motorways: in the case of intersections (i.e. in an urban environment) the calibrated value of $T$ is lower (by $29 \%$ ), and the calibrated value of $a$ is higher (by $28 \%$ ).

\section{Acknowledgements}

This research is supported by TÁMOP-4.2.2.C11/1/KONV-2012-0012: "Smarter Transport" - IT for co- 
operative transport system - The Project is supported by the Hungarian Government and co-financed by the European Social Fund.

\section{References}

[1] Helbing, D. Fundamentals of traffic flow. // Physical Review E. 55, (1997), pp. 3735-3738. DOI: 10.1103/PhysRevE.55.3735

[2] Péter, T. Modeling nonlinear road traffic networks for junction control. // International Journal of Applied Mathematics and Computer Science. 22, 3(2012), pp. 723732. DOI: $10.2478 / \mathrm{v} 10006-012-0054-1$

[3] Péter, T.; Fazekas, S. Determination of vehicle density of inputs and outputs and model validation for the analysis of network traffic processes. // Periodica Polytechnica, Transportation Engineering. 42, 1(2014), pp. 53-61. DOI: 10.3311/PPtr.7282

[4] Péter, T.; Szabó, K. A new network model for the analysis of air traffic networks. // Periodica Polytechnica, Transportation Engineering. 40, 1(2012), pp. 39-44. DOl: 10.3311/pp.tr.2012-1.07

[5] Wiedemann, R. Simulation des Straßenverkehrsflusses. // Schriftenreihe des Instituts für Verkehrswesen, Vol. 8, Institut für Verkehrswesen, Universität Karlsruhe, 1974

[6] Fritzsche, H. T. A model for traffic simulation. // Traffic Engineering and Control. 35, 5(1994), pp. 317-321.

[7] Wiedemann, R. Modelling of RTI-Elements on multi-lane roads. // Advanced Telematics in Road Transport, Proceedings of the Drive Conference, Brussels, (1991), pp. 1001-1011.

[8] Apeltauer, T.; Macur, J.; Holcner, P.; Radimsky, M. Validation of Microscopic Traffic Models Based on GPS Precise Measurement of Vehicle Dynamics. // PrometTraffic \& Transportation. 25, 2(2013), pp. 156-167. DOl: 10.7307/ptt.v25i2.1293

[9] Treiber, M.; Hennecke, A.; Helbing, D. Congested traffic states in empirical observations and microscopic simulations. // Physical Review E. 62, (2000), pp. 18051824. DOI: $10.1103 /$ PhysRevE.62.1805

[10] Treiber, M.; Kesting A. Traffic Flow Dynamics - Data, Models and Simulation. Springer-Verlag Berlin 2013. pp. 181-204. DOI: 10.1007/978-3-642-32460-4_11

[11] Schakel, W. J.; Knoop, V. L.; van Arem, B. LMRS: An Integrated Lane Change Model with Relaxation and Synchronization. // Transportation Research Record: Journal of the Transportation Research Board. 2316, (2012), pp. 47-57.

[12] Treiber, M.; Helbing, D. Microsimulations of Freeway Traffic Including Control Measures. // Automatisierungstechnik. 49, (2001), pp. 478-484. DOl: 10.1524/auto.2001.49.11.478

[13] Thiemann, C.; Treiber, M.; Arne Kesting, A. Estimating Acceleration and Lane-Changing Dynamics from Next Generation Simulation Trajectory Data // Transportation Research Record: Journal of the Transportation Research Board. 2088, (2009), pp. 90-101.

[14] Caprani, C. C. Calibration of a Congestion Load Model for Highway Bridges Using Traffic Microsimulation. // Structural Engineering International. 22, 3(2012), pp. 342348. DOI: 10.2749/101686612X13363869853455

[15] Derbel, O.; Péter, T.; Zebiri, H.; Mourllion, B.; Basset, M. Modified Intelligent Driver Model. // Peridoica Polytechnica-Transportation Engineering. 40, 2(2013), pp. 53-60. DOI: $10.3311 /$ pp.tr.2012-2.02

[16] Yang, S. Enlarged Stopping Distance to Improve Vehicle Distance at Urban Signalized Intersections. // PhD Thesis, Queensland University of Technology, 2013.
[17] Dey, P. P.; Nandal, S.; Rahul Kalyan, R. Queue Discharge Characteristics at Signalised Intersections under Mixed Traffic Conditions. // European Transport-Trasporti Europei. 55, 8(2013), pp. 1-21.

[18] Lee, H. S.; Do, T. W. Saturation Headway of Through Movement at Signalized Intersections in Urban Area. // Journal of Transportation Research Society of Korea. 20, 5 (2002), pp. 23-31.

[19] Jumsan, K.; Sungomo, R.; Zunhwan, H. Vehicle Passing Behaviour through the Stop Line of Signalised Intersection. // Journal of the Eastern Asia Society for Transportation Studies. 6, (2005), pp. 1509-1517.

\section{Authors' addresses}

Tamás Kovács, PhD

Kecskemét College, GAMF, Department of Informatics Izsáki 10, 6000 Kecskemét, Hungary

E-mail:kovacs.tamas@gamf.kefo.hu

\section{Kálmán Bolla,}

Kecskemét College, GAMF, Department of Informatics 6000 Kecskemét Izsáki 10

E-mail: bolla.kalman@gamf.kefo.hu

\section{Rafael Alvarez Gil, PhD}

Kecskemét College, GAMF, Department of Informatics 6000 Kecskemét Izsáki 10

alvarez.rafael@gamf.kefo.hu

Edit Csizmás,

Kecskemét College, GAMF, Department of Informatics 6000 Kecskemét Izsáki 10

E-mail: csizmas.edit@gamf.kefo.hu

\section{Csaba Fábián, PhD}

Kecskemét College, GAMF, Department of Informatics 6000 Kecskemét Izsáki 10

E-mail: fabian.csaba@gamf.kefo.hu

\section{Lóránt Kovács, PhD}

Kecskemét College, GAMF, Department of Informatics 6000 Kecskemét Izsáki 10

E-mail: kovacs.lorant@gamf.kefo.hu

\section{Krisztán Medgyes,}

Kecskemét College, GAMF, Department of Informatics 6000 Kecskemét Izsáki 10

E-mail: medgyes.krisztian@gamf.kefo.hu

\section{József Osztényi, PhD}

Kecskemét College, GAMF, Department of Mathematics 6000 Kecskemét Izsáki 10

E-mail: osztenyi.jozsef@gamf.kefo.hu

\section{Attila Végh, PhD}

Kecskemét College, GAMF, Department of Mathematics 6000 Kecskemét Izsáki 10

E-mail:vegh.attila@gamf.kefo.hu 